\title{
ICT platforms and regulatory concerns in Europe
}

\section{Introduction}

ICT systems and services are increasingly characterised by technical and product modularity. Modularity refers to the design of systems and artefacts as sets of discrete modules that connect to each other via predetermined interfaces, and is a practical solution to deal with the increasing complexity and systemic nature of ICTs (Baldwin \& Clark, 2000). This development has prompted some authors to expect an era of market modularity, in which competition between small, unbundled companies flourishes, and regulatory concerns dissipate (see e.g. Langlois, 2003). Instead, it is now becoming accepted knowledge that in such a context, platforms arise as central components that enable their providers to operate as gatekeepers of information and value flows between multiple groups of stakeholders (Gawer, 2009a). High-profile ICT platforms include the Apple or Google smartphone and computer platforms, that act as gatekeepers towards a.o. content and application providers; and the digital TV platforms of cable, DSL and satellite operators such as Sky or Numericable, which are gatekeepers of TV broadcast channels, end-user interactivity and even advertisements.

The emergence of these so-called multi-sided platforms implies that policy makers and regulators should not take for granted that simply allowing and facilitating the convergence between IT, internet, telecommunications and media services and technologies will result in an unbundled, open marketplace in which competition will flourish (Ballon, 2009). Rather, the bottleneck function of platforms may trigger serious regulatory concerns, and may prove to be harder to delineate and to regulate than bottlenecks in the current access operator market. On the other hand, the specific nature of platforms implies that many traditional suspicions against firms setting non-cost oriented prices, introducing cross-subsidies and engaging in collaborations to set a de facto industry standard, lose (some of) their validity in a multi-sided market context (Poel et al, 2007; Wright, 2004). This article will argue that this requires policy makers and regulators to acknowledge and incorporate the platform logic and characteristics into electronic communications regulation.

There are other challenges for regulators. Increasingly, platforms originating in entirely different sectors compete directly against each other. One example are mobile application stores, web portals, mobile phone operating systems, and network operator platforms, all attempting to be the main entry point for the consumption of applications on smartphones. It will be argued here that the aim of not putting one particular class of competing platforms at a disadvantage, is likely to lead to a certain regulatory convergence, in the sense that access operators may become regulated more lightly, and other platform owners more heavily, than 
is the case today. This implies that platform activities should be considered and appraised according to their business model within the converged ICT landscape, instead of according to the specific activities performed within the isolated relevant markets as they are commonly defined in Europe today.

The first objective of this article is therefore to highlight the particular relevance of platform analysis for understanding present-day developments in ICT markets. To this end, the article identifies various types of platform business models in ICT markets and analyses them according to the form of control that is exercised by the platform owner. The second objective is to indicate how such analysis could be taken on board in the regulation of electronic communications and ICT markets in Europe. This exploratory exercise will take the form of a preliminary assessment of whether and how existing regulatory frameworks may accommodate regulation that is more platform aware.

The outline is as follows. First, the concept of platforms, arising around crucial gatekeeper functionalities, is introduced. Subsequently, it is argued that ICT markets are particular platform markets in the sense that they harbour a large variety of platform business models, which can be fitted into a platform typology. Following this, a short introduction is given related to EU policy concerns over platforms, and a number of potential tools for regulatory intervention are outlined. Finally, these are related to potential regulatory concerns for the platform types that can be distinguished, so as to arrive at a number of prescriptive suggestions for regulation.

\section{The rise of platforms}

A central feature of ICT products and services is their modularity. The key question in research on modularity is the mirroring hypothesis, that is the hypothesis that technical and product modularity will be reflected in firm and industry modularity (Baldwin, 2007; Colfer, 2007). As the most prominent defender of the mirroring hypothesis, Langlois (2003) has argued that modular product and process architectures have made hierarchical coordination in many instances unnecessary. As a result, he has argued that the Chandlerian visible hand of big corporations is vanishing, and that vertical integration in industries is increasingly disappearing. Others such as Ernst (2005) have been more cautious, and have concluded that technical modularity is a necessary but not sufficient condition for market modularity. Still others have asserted that modularity would even lead to various new forms of vertical coordination, that is to "System Integrators not Legoland" (Pavitt, 2003), because of significant limits to the division of labour in many industries. 
It can be argued that the nascent body of platform theory (Gawer, 2009a; Mikkola \& Hansen, 2005; Roson, 2005) sketches out the contours of a potential synthesis of this dialectic between modular and integrated design architectures, and market structures. Gawer \& Cusumano (2002) have characterised the appropriate strategy for firms operating in the context of modular ICT systems, as the quest for platform leadership. This refers to the strategic objective to control a central system module around which other companies may develop a range of complementary technologies and products. It has been confirmed by West (2003) that leading ICT firms are increasingly opting for hybrid, 'open but not open' strategies that attempt to combine the advantages of open technology development while retaining the ability to control and differentiate. In effect, the success of firms such as Intel, Microsoft, Google, Facebook and Apple has been attributed to the fact that they have been able to position themselves as 'platforms' within their business ecosystem. Moreover, the main dynamics and upheavals affecting ICT markets today are increasingly being framed, either implicitly or explicitly, as resulting from the struggles between IT, internet, telecom and media giants for platform leadership within a converged ICT landscape (see e.g. Greenstein, 2009).

Consequently, the concept of platforms, their characteristics and behaviour, have become increasingly singled out for deeper analysis. While platforms in manufacturing are an established concept (Meyer \& Utterback, 1993; Wheelwright \& Clark, 1992), it is often remarked that platforms in information products industries may require a different set of concepts (Salonen, 2004; McGrath, 2001; Bresnahan, 1999). Technically, an ICT platform may refer to a hardware configuration, an operating system, a software framework or any other common entity on which a number of associated components or services run. Economically, platforms and their providers mediate and coordinate between various stakeholder constituencies. Platform owners' business models, rather than to focus on profit maximisation in a single market, primarily deal with getting the various stakeholder groups on board, with balancing interests between these groups and with balancing openness and lock-in of customers (Cortade, 2006). It has also been stressed that ICT platforms have a durable and structural character (Bresnahan, 1999). This results from the fact that they have interchangeable components, so that many buyers can share the benefits of the same technical advance, introducing network effects into the economics of ICT platforms, and causing platforms to be hard to start, hard to stop, but generally easy to maintain.

Most literature refers to the concept of bottlenecks to explain how platforms arise. Baldwin and Clark (2006) suggest that successful firms are those that possess architectural knowledge about bottlenecks and use this knowledge in order to shrink their footprint and selectively outsource activities. In this way, they gain an advantage in terms of invested 
capital, while keeping control over the most critical bottlenecks. Similarly, Jacobides et al (2006) argue that firms can benefit from innovation by managing the industry's architecture carefully so they become the bottlenecks of their industry. Jacobides et al. (2006) envisage bottleneck ownership and exploitation in terms of architectural advantage, and define bottlenecks in a strategic way, that is as segments where mobility (both in terms of switching costs and potential entry) is limited and competition is softened.

Another common explanation of platform ownership lies in the ownership and specification of particular critical interfaces (Gawer \& Cusumano, 2002). Obviously, the question is then why interfaces arise at certain points. Baldwin (2007) has provided an argument for this based on transaction cost theory. She argues that interfaces tend to arise at thin crossing points within a task network. Thin crossing points are associated with low transaction costs, (e.g. the costs of defining, counting, and paying for things transferred) and with information hiding between the various stakeholders.

The related concept of gatekeeper functionalities (Ballon, 2009) adds the dimension of critical information processing capabilities to the bottleneck and transaction cost arguments. It joins the idea of the role of a platform gatekeeper (see e.g. Farrell \& Weiser, 2003; Baye \& Morgan, 2001), controlling access in modular or partly-modular systems, with the concept of information gatekeepers, which is commonly used in media and communication studies to describe persons and organisations selecting and processing ideas and information (see e.g. Shoemaker, 1996; Lewin, 1951). Included in this concept is the notion that gatekeepers not only filter and select information (i.e. the gatekeeper acts as a bottleneck) but also qualitatively alter the informational content (for better or for worse) through active accumulation, processing and packaging (i.e. the gatekeeper adds critical 'value'). The gatekeeper concept is thus linked to specific information gathering, processing and filtering functionalities that enable its owners to adopt a platform position within the value network.

In the context of ICT platforms, this implies that gatekeeper functionalities, corresponding to a number of specific business roles, are instrumental in strategies to make available information and communication resources and thereby attract great numbers of customers, but at the same time allow to control various types of customers. This double function also refers to the concept of a 'business model' as the specific way in which value and control parameters are configured within a certain value network, and to which a whole 'ecosystem' of stakeholders, willingly or not, adheres (Ballon, 2007a). A platform should therefore not be considered as a given architectural and organisational entity, but as a collection of a number of crucial gatekeeper roles that may be used to attract as well as to lock in (at least to some extent) various types of customers. These roles may be configured in various ways and at various levels of the technical architecture, and may be owned and 
operated by different business entities. Only when considered in this way, does it become conceivable that companies specialising in completely different system components, such as telecom networks, end-user devices, operating systems (OSs), web browsers, content portals, web applications, and so on, could be involved in head-on competition for platform leadership in various ICT markets.

It can be summarised that, rather than modularisation, ICT markets are instead characterised by far-reaching 'platformisation' (Ballon, 2009). In such markets, platform leaders have built a business model around a set of crucial gatekeeper functionalities and roles that help them to exercise a form of control over the wider value network, and to add and capture significant value in the process. The form that this control takes in practice may differ and shift strongly between various platforms, and as platforms evolve. This is still a rather under-researched area. There is a growing body of literature that is focused on highlighting and formalising competition between platforms. However, as the next section argues, more attention should be devoted to shifting platform strategies and business models, and the associated control configurations, especially when analysing platforms in ICT markets.

\section{Platform Behaviour and Competition in ICT Markets}

Two-sided and multi-sided networks literature refers to platforms as mediating entities between agents that operate on different sides of the market, and whose utility is affected by participation and usage on the opposite side(s) (see e.g. Armstrong, 2004; Jullien, 2004; Rochet \& Tirole, 2003). Much of this literature offers a rather 'static' analysis in the sense that it concentrates on price equilibrium and allocative efficiency for a single platform or in relation to competition between two platforms. It has been argued that the indirect (i.e. between the groups at different sides of the platform) externalities that characterise platforms are linked to their function as 'informational intermediaries' (Caillaud \& Jullien, 2003), so ICT platforms can be considered as typical cases in point. However, although most authors incorporate at least some examples from the ICT industry, relatively few have pointed at any specific characteristics of platforms and platform competition in the ICT domain.

Still, some particularities have been noted. First, ICT-specific literature on platform markets tends to stress the dynamic and complex nature of competition between a large number of platforms or platform 'wannabes'. For instance, Church \& Gandal (2005) have pointed at the drawn-out standards wars related to the Instant Messaging, 56K Modems and mobile cellular markets, highlighting a considerable number of dynamically evolving factors affecting the establishment and behaviour of platforms. 
Also, authors writing on the specifics of two-sided markets in the ICT domain tend to emphasise the influence of technological configurations. In the ICT industry, controlling a platform in the economic sense is commonly (yet not necessarily) associated with controlling a platform in the technological sense, i.e. a hardware configuration, an operating system, a software framework or any other common entity on which a number of associated components or services run. Issues of interoperability, of open and proprietary interfaces and standards, and of bundling and adding features by the platform are much more pronounced in the ICT industry than in most other industries (see e.g. Evans et al, 2005).

Third, these authors often imply that there is a greater scope in the ICT domain for strategic decision-making regarding the option of organising a business as a platform market. So, the decision to adopt a multi-sided platform strategy, similar to the decision whether or not to vertically integrate, does not have an evident outcome in many ICT markets, and may evolve rapidly, dependent on the specificities of the evolving technology and market environments.

Finally, authors (Boudreau \& Hagiu, 2009; Spulber, 2009) have also pointed at the role of digital (but also non-digital) platforms as "private regulators", who use "nuanced combinations" of legal, technological, informational and other instruments that are far more extensive than simply 'getting prices right'.

Despite such valuable attempts to contextualise platforms and platform markets, the notion of a platform is still mostly considered as a given, i.e. as an abstraction that allows generally valid analysis and comparison. In opposition to this, and particularly in relation to studying the ICT industry, a number of authors (Parker \& Van Alstyne, 2008; Ballon, 2007b; Boudreau, 2005) argue that real-life platforms exhibit strong heterogeneity in terms of the configuration of components and boundaries, in terms of integration and compatibility strategies, of revenue (sharing) models and even in terms of the associated regulatory concerns - to the point that the terms 'platform' and 'platform strategy' to capture all these initiatives lose most of their explanatory power.

Consequently, they argue that research needs to abandon abstract and static conceptions of a "platform", and instead should concern itself with changing boundaries of platforms, different types of platform business models, and various levels of integration and control.

\section{A Typology of Platform Business Models}

Delving further into this notion of different types of (ICT) platforms exerting different forms of control in the market through the employment of different business models - and 
thus potentially giving rise to different regulatory concerns -, the first step to refine the analysis of platform markets is to introduce a platform typology, based on the control configurations associated with these platforms. This platform typology (originally introduced in Ballon, 2009) takes as point of departure the notion that all platforms aim at the control over a set of crucial 'gatekeeper functionalities' (see above), but may differ fundamentally both in terms of the control they have over the set of additional business roles that they integrate beyond this, and over the so-called end customers of the platform.

Rather few authors have devoted attention until now to the specific characteristics of, and differences between, several types of platforms. And while a few authors have tentatively put forward platform typologies, their supposedly mutually exclusive categories are more often than not found in combination in the ICT industries. This is true for the distinction between active matching versus passive mediation services of Schiff (2003), proprietary versus shared technologies as proposed by Eisenmann (2007), and the matchmaking, audience making, transaction-based and 'shared-input' platforms of Evans et al (2005). In addition, Gawer (2009b) has recently introduced a more general typology of platforms composed of platforms that are internal to firms, supply chain platforms, and industry platforms. While it is a useful conceptual distinction, it has less direct merit for the topic of this article, as it does not allow in itself to distinguish the potential competitive bottlenecks involved.

The platform typology adopted here instead distinguishes between platforms according to the control they exert beyond the gatekeeper functionalities. As argued above, platform leaders can be defined as agents operating crucial gatekeeper roles. However, this does not necessarily mean that the platform owner also has control over the customer (i.e. end-user) relationship, or has control over the assets needed to 'assemble' the value proposition of the goods and services traded over the platform. In fact, this typology reflects the central tenet of platform literature that these forms of control can and will to an extent reside outside of the platform (making the platform model 'open'), while the platform only monopolises control over the roles that bestow most 'architectural advantage' (making the platform model 'open but not open'). Reinterpreting the business models currently employed in the ICT industry in this light, four basic platform types can be distinguished (see also Ballon, 2009).

The first type of platform, that keeps its distance from the eventual value proposition as well as from the customer relationship, can be labelled a 'Neutral Platform'. This refers to a case in which the platform owner does not control most of the assets necessary for the value proposition (because apart from controlling the gatekeeper roles it has hardly any assets related to the value proposition itself), and on top of this does not have customer ownership (because it does not establish a billing relationship with the end-user and may be even 
invisible to the end-user). Paypal and Google search are typical cases in point. The Google search engine platform, for instance, does not intervene with the specification or offering of the content and services to which it refers people. Also, customer lock-in is minimal, and no subscription or billing relationship with the user exists. Still, Google is able to internalise a significant part of the externalities created, through the capturing of advertisement revenues, both on its search portal and on a significant number of affiliated websites.

The second type could be labelled a 'Broker Platform'. In this case, the platform relies on other actors that control most of the assets for establishing the value proposition, but does integrate customer ownership. Facebook and eBay are typical examples of such a broker platform. In the case of eBay, the independent sellers provide the value proposition to the buyers, with eBay merely offering the place where both constituencies meet. Yet, in terms of the customer relationship, people are very aware of the brand (and associated guarantees) of eBay, and generally do not know or care about the seller's identity (except for the data on past purchases, which eBay provides). Also, eBay supports the transaction and billing process, which is another important aspect of customer ownership.

The third type of platform can be labelled an 'Enabler Platform'. This refers to the case where the platform owner controls many or most of the assets involved in service provision, but leaves the customer relationship to third-party developers. The IMS platform or the Intel platform may be seen as examples of this type. For instance, Intel has a firm grip on the hardware architecture, standards and application programming interfaces, and represents of a large part of the value-add, of any Intel-powered Personal Computer (PC). Thus, it controls several of the assets involved in the PC value proposition, which is highlighted by the 'Intel inside' quality label. At the same time, the main PC brand that consumers recognise is still that of the PC manufacturer, who also takes care of the marketing, sales and aftersales through its retail channels.

The fourth type of platform can be labelled a 'System Integrator Platform'. This represents the case where many or most of the assets related to the value proposition, as well as the customer ownership, are in the hands of the platform owner. Still, this actor actively facilitates and encourages entry of 'third parties' to constitute a multi-sided market, e.g. by not 'squeezing' complementary actors out of the market. In other words, it allows competing service providers to use its platform, in order to increase the value of both this platform and its own end-user service offering. Typical examples of such a platform model are the Microsoft Windows Platform and the Apple iPhone. In the case of the iPhone, Apple controls the hardware, OS and other middleware components, the App Store portal and transaction system, as well as several individual applications themselves. It is able to extract significant rents and set barriers to exit for application providers. Moreover, it controls the relationship 
with end-users in terms of branding, finding and selecting applications, and paying for it. Still, it acts as a platform, actively promoting the addition of a multitude of application developers to the iPhone application 'ecosystem' through an easily available software development kit, application developer programmes, a transparent and uniform revenue sharing model, and so on.

This bird's eye overview illustrates the diversity of various (and often competing) ICT platforms. It also demonstrates that platforms that control the same gatekeeper roles (e.g. collecting and processing profile data, or enabling transactions), may have radically different types of business models, dependent on to what degree they control the value proposition and the customer relationship of the services that make use of the platform. In summary, the proposed platform typology, based on these control and value-related parameters, can be represented as follows:

Table 1: Typology of Platform Models (see also Ballon, 2009)

\begin{tabular}{|c|c|c|}
\hline & No Control over Customers & Control over Customers \\
\hline \multirow{3}{*}{$\begin{array}{l}\text { No Control over } \\
\text { Assets }\end{array}$} & Neutral Platform & Broker Platform \\
\hline & $\begin{array}{l}\text { The platform owner is strongly } \\
\text { reliant on the assets of other actors } \\
\text { to create the value proposition, and } \\
\text { does not control the customer } \\
\text { relationship }\end{array}$ & $\begin{array}{l}\text { The platform owner is strongly } \\
\text { reliant on the assets of other actors } \\
\text { to create the value proposition, but } \\
\text { does control the customer } \\
\text { relationship }\end{array}$ \\
\hline & Examples: Google search, PayPal & Examples: Facebook, eBay \\
\hline \multirow{3}{*}{$\begin{array}{l}\text { Control over } \\
\text { Assets }\end{array}$} & Enabler Platform & System Integrator Platform \\
\hline & $\begin{array}{l}\text { The platform owner controls many } \\
\text { of the necessary assets to ensure } \\
\text { the value proposition, but does not } \\
\text { control the customer relationship }\end{array}$ & $\begin{array}{l}\text { The platform owner controls many } \\
\text { of the assets to ensure the value } \\
\text { proposition, and establishes a } \\
\text { relationship with end-users. Entry } \\
\text { of 'third-party' service providers is } \\
\text { actively encouraged }\end{array}$ \\
\hline & Examples: Intel, IMS & $\begin{array}{l}\text { Examples: Apple iPhone, Microsoft } \\
\text { OS }\end{array}$ \\
\hline
\end{tabular}

Naturally, this typology needs to be further refined and validated. However, we suggest that it may serve to operationalise various forms of control leading to different platform 
models, to explore the different characteristics of the platform types and to link these to various outcomes in terms of value being created for service developers as well as for end users.

\section{Platforms and Regulatory Concerns}

The bottleneck function of platforms, and the various control patterns that can be distinguished in platform business models, indicate that a specific analysis of the potential regulatory concerns may be useful. The following sections explore the relevance of platforms for the current European regulatory framework, and vice versa.

When assessing the impact of market developments on regulation, two fundamental questions typically impose themselves, i.e. whether ex ante intervention is necessary/desirable or not; and, related to this, whether sector-specific regulation is necessary/desirable or not. In this context, it needs to be considered that competition law in principle (but not always) intervenes after the fact, and is triggered by intended (e.g. in the case of a notification of a merger) or perceived behaviour. This may create a number of issues in fast evolving sectors such as the ICT industry. In contrast, sector-specific regulation intervenes ex ante, by imposing rules even when there is no abusive conduct, but only the potentiality of abuse according to EU guidelines. This causes an asymmetrical situation, in which obligations are enforced upon the strongest players, and rights bestowed upon weaker players.

In electronic communications, access operators are historically regulated in an ex ante fashion because they are deemed to control essential facilities and because the prospects for competition are regarded as limited. In other parts of the ICT industry, dominant players are regulated ex post under competition law. Still, it is important to realise that sector-specific, ex ante regulation is based methodologically on the rules of competition law, pertaining e.g. to the delineation of markets, the assessment of individual or common dominance or significant market power, the identification of market failure due to barriers to market entry, and eventually the imposition of remedies. In fact, it has been argued that since the introduction of the so-called new regime for regulating electronic communications services, which came into force in Europe in 2003, sector-specific regulation in the electronic communications sector has evolved towards a sort of 'ex ante anti-trust framework' (Cave, 2004; De Streel, 2004). In general, this framework can be characterised as mainly focused on the analysis and regulation of specific, isolated, 'one-sided' markets (Wauthy, 2008; Poel et al, 2007).

The emergence and pervasiveness of platforms seemingly necessitate a reappraisal of some of these basic orientations. First of all, it can be argued that platforms should be at the 
centre of attention of regulators. It was already indicated that the abundance and commoditisation created on different sides of a multi-sided platform is as a rule accompanied by various business models and strategies of control and scarcity around a set of gatekeeper functionalities. Platforms, by their nature, exhibit strong concentration tendencies, because of the network effects inherent in platforms (Wauthy, 2008; Bresnahan, 1999). Also, they have the potential to exert market power into adjacent markets, i.e. those markets for complementary products and services.

Therefore, the value of 'open' or neutral platforms, allowing multihoming of service providers and end-users, as well as the importance of inter-platform standardisation, including voluntary or mandated compatibility, interoperability, and interconnection, have been stressed by several authors (see e.g. Johnson, 2009; Church \& Gandal, 2005), even though there is no consensus around any potentially associated regulatory measures. In any case, such arguments also appear to underlie the current calls for net neutrality, i.e. the ex ante regulation of telecom operators' involvement in, and treatment of, internet content and services. In the $\mathrm{EU}$, the initial reluctance to resort to mandated net neutrality seems to have lessened to some extent, and a public consultation on net neutrality was opened in 2010 (see e.g. Marsden, 2010; Renda, 2008).

Net neutrality can be interpreted as imposing 'platform neutrality' at the access operator level. However, the typology and examples proposed earlier suggest that platforms may arise practically everywhere within the ICT industry, and that direct competition is feasible between platforms operating in entirely different parts of the value chain. This also means that access operators are no longer the only type of player exploiting bottlenecks or controlling the electronic communications market. Therefore, it seems fair to say that concerns over abuse of market power should not be limited to access operators alone. In fact, several pleas have already been made for policy makers and regulators, who have so far focused mainly on access operators, to adapt to this new situation, and to evolve towards some kind of 'platform neutrality' (see e.g. Williamson \& Marks, 2009; Arino, 2007).

The recent Digital Agenda for Europa appears to acknowledge the need to adapt the regulatory framework to the reality of platform markets. It was launched by EU commissioner Kroes in May 2010 as a comprehensive action plan, to be implemented through a range of follow-up actions including legislative proposals. It identifies seven priority areas for action, i.e. creating a digital Single Market, greater interoperability, boosting internet trust and security, much faster internet access, more investment in research and development, enhancing digital literacy skills and inclusion and applying information and communications technologies to address challenges facing society like climate change and the ageing population. One striking aspect of the Digital Agenda is that it foresees new European 
interoperability rules for the electronic communications industry, based on antitrust rules related to the abuse of market position, referring in this case to a significant, instead of dominant, position. In this case, obligations will be imposed related to licence interoperability information, to ensure consumer choice in software as well as hardware. It should be noted that this pertains to technical platforms, while the analysis in this paper extends also to pure service platforms.

In the same context, Commissioner Kroes has expressed concern over the market position and conduct of Apple, in particular in relation to the interoperability between various smartphone platforms. Observers disagree about the extent to which a similar case can be built by the Commission, as was done related to the openness of the Microsoft platform. Meanwhile, the EU announced that it would drop two anti-trust investigations related to the Apple iPhone platform. One issue for any intervention is to determine the appropriate 'relevant market' (see further). Another issue is that, as argued by Wauthy (2008), currently no clear, general principle exists about how to regulate platforms, and regulators have no operational frameworks that can easily accommodate the particular characteristics of platform markets - such as the existence of externalities across different sides of the platform, and the complex effects of multi-homing of service providers and/or end users. Still, it is clear that there is a growing awareness of and concern over the position and potential abuse of market power by platform owners in the electronic communications industry.

However, the characteristics of platforms provide also a number of reasons to mitigate concerns and/or intervention. A platform coordinates interactions between two or more distinct groups of stakeholders and is able to internalise the externalities created by one group for the other group. Business models in multi-sided platform markets, rather than to focus on profit maximisation in a single market, primarily deal with getting the various stakeholder groups on board, balancing interests between these groups and with single- or multi-homing of customers (i.e. whether customers are tied to one or more platforms) (Evans, 2003). This means that, in a multi-sided market, a viable pricing strategy could consist of subsidizing one side to attract customers on the other. This implies that competition policy analysis cannot consider prices separately, and should not regard a strategy based on cross subsidies as predatory in many instances (Cortade, 2006; Wright, 2004).

It has also been argued that regulators who impose price regulations and other restrictions on one specific (type of) actor(s), seldom take into account the impact of such regulation on the entire value network, which is especially relevant in the case of multi-sided platforms. Also, they regularly fail to distinguish between bundling as an integral part of any multi-sided platform business and 'bundling as a way to leverage monopoly', and may be overly suspicious of collaboration between competitors within the same layer in view of 
creating a de facto industry standard. It follows that policy makers and regulators ought to use a more holistic framework, which may shift the emphasis from traditional policy analysis based on specific policy domains or isolated 'relevant markets', towards the relevant determinants for successful platform models (Poel et al, 2007).

Pardolesi \& Renda (2004) give the example of the 2004 European ruling against Microsoft for leveraging its market power in the client PC operating system market into the adjacent market of servers. They argue that the standard way of market definition that was performed and the subsequent condemnation of Microsoft for preserving privileged connections between its client PC platform and its work group server operating system, are both deeply flawed, because they fail to take into account that Microsoft was not merely competing in the server market, but rather against much more encompassing 'razor-andblade' (i.e. built around cross-subsidisation between server sales and service contracts) business models used by competitors such as Sun and IBM.

In summary, there have traditionally been reasons for regulating some platforms and not others. In electronic communications, access operators are regulated in an ex ante fashion because they control essential facilities and because the prospects for competition are regarded as limited. In other parts of the ICT industry, dominant players are regulated ex post under competition law. Under the new Digital Agenda, Europe appears to open the door towards regulating platforms in general, i.e. the access to platforms, the interoperability between platforms, and so on. However, it seems that no operational framework currently exists that can easily accommodate the specific characteristics of platforms. Also, it was argued that for any platform regulation to be effective and not to veer into over-regulation, it is indispensable to take into account the specific business models employed by the platform owners. The remaining sections will focus on the applicability of the current regulatory framework, and will propose a number of directions for taking into account platform business models.

\section{Tools for Regulatory Intervention}

This section deals with the way regulators may intervene in platform markets, if at all necessary, to ensure the development of the market and citizens' rights to pluriformity, choice, affordable tariffs, quality and innovation, and which role the existing ex ante and ex post frameworks can play in this. First, it will be argued that there is a need to start a theoretical analysis at the EU level on the competitive risks and regulatory challenges posed by various platform models. Second, it is proposed that anti-trust and sector-specific approaches towards platform regulation can be complementary, and that specific cost-benefit 
analyses need to be performed to determine whether ex ante regulation of specific platform models is necessary. Third, the applicability of the three-step approach, which is somewhat similar in both ex post and ex ante regulation, and the new recommendation on next generation access networks, are briefly discussed.

It was already asserted that at this stage, one of the primary issues for regulators is the lack of any framework or set of principles with which to approach platform markets. Given the lack of practical expertise related to this matter among European regulators, it appears to be a valid approach to start with a more theoretical exercise, related to building a number of hypotheses on potential problems, related to various platform models. This may be followed by an analysis of the probability and impact of any distortion of competition. Because of the often limited grip and oversight of national regulators related to ICT platforms, and for harmonisation reasons, it seems that this should take place primarily at the European level (see also further).

The European Commission (EC), in cooperation with the European Regulatory Group (ERG) - which has been more or less transformed meanwhile into BEREC (Body of European Regulators for Electronic Communication) - in fact performed a similar analysis at the time of liberalising the telecom markets, and afterwards when reviewing the directives. This has led to a corpus of rules, based on theory as well as on practice, for regulating the electronic communications market. Those rules are sector-specific, but closely linked to competition law. They are almost exclusively aimed at the access markets, i.e. at the regulation of networks, as up to the present day this has been an area characterised by major competition issues. This then raises the issue whether, mutatis mutandis, this method might be applicable in the context of multi-sided markets at different levels of the industry.

Related to the applicability of anti-trust versus sector-specific approaches, recent studies have indicated that antitrust and sector-specific regulations in the ICT domain, while converging to some extent, will remain complementary in the foreseeable future, in the sense that antitrust regulation is best equipped to deal with the conduct of economic agents, while sector-specific regulation may be preferred to tackle a number of issues related to market structure. De Streel (2008), for instance, argues that sector regulation should (only) be applied when it is more efficient than antitrust to solve market failures, i.e. when there are vertical chains of production rather than horizontal markets, structural (economic or legal) entry barriers, or network effects across multiple sides of the market. It is clear that platform markets fall within this scope. He also proposes that, in order to alleviate confusion between antitrust and sector regulation objectives, it would be better to base sector regulation on an independent economic concept linked to the goals of regulation. In this respect, authors such as Richards (2006) and Larouche (2000) have argued that sector regulation should centre on 
the concept of 'bottlenecks'. Again, the link to the gatekeeper function of platforms is evident. The subsequent section of this paper will therefore further follow this approach. Still, it should also be remarked that, in such a complex situation, a cost-benefit analysis of ex ante regulation will be absolutely necessary. This is because the danger of over-regulating and substantially slowing down market developments is real (see also Renda, 2008).

Turning to the experience of EU regulation in the electronic communications domain, this is primarily contained in two Directives, i.e. the Access Directive and the Universal Service Directive (2002 ${ }^{1}$ ); in a Recommendation related to relevant markets; and in an ERG paper (ERG, 2005) on the method for market analysis. In summary, the methodology demands that the National Regulatory Agencies (NRAs) take a three step approach before applying regulation. It is important to note that they have to perform a sort of Cost/Benefit analysis to assess whether their planned measures make sense. This anticipates in a sense the assessment between ex post and ex ante intervention.

The three steps are the following. First, there is the market definition. NRAs need to carefully delineate which very specific parts of the access markets will be analysed and if necessary will be subjected to remedies. This delineation is in large part based on the principles of competition law. The EC has taken this work out of the hands of the NRAs, by pre-defining an initial number of 18 markets, and subsequently, after a number of years of experience, limiting this to 7 markets (Commission Recommendation of 17 december 2007).

Even though the Commission set up a complex system for NRAs to use when defining markets, the EC itself thus put forward a purely theoretical approach. The EC had veto power against irregular decisions in the Member States. This led de facto to the paradoxical situation that the factual determinations of the NRA risked to be forced into the framework of the 18 , and subsequently 7, markets. In essence, the burden of proof was reversed, and the NRAs were obliged to prove that some of these market definitions were irrelevant. A case in point is the history of market 17 , the roaming market, for which the EU in the end had to take the necessary decisions itself for it to be regulated at the European level. One may consider in this respect that the NRAs were unable to solve this issue, as they were incapable of regulating termination tariffs of foreign operators. Also, Europe was in this case imposing a decision that contradicted its own rules in two ways, i.e. by not applying the three-step approach, and by imposing maximum retail tariffs. All of this does not imply that such a theoretical exercise is not necessary, but rather that it should not be overly rigid, so as to define market segments that are relevant to the existing competition issues, and that the institutional design of European regulation is lacking in this respect.

\footnotetext{
${ }^{1}$ It was reviewed in December 2009, with no major impact on the topic of this paper, except concerning net neutrality and net freedom; see further.
} 
It should be noted in this respect that market definitions necessarily also entail an investigation into the position of users. Instead of being involved merely as passive consumers, they determine, through their choices, and the cross-market externalities, the value and market shares of the specific platforms (see also Caillaud \& Jullien, 2003). Those choices are influenced by several factors, including tariffs, technologies, service offerings, expectations about the success and durability of a specific platform, usability, and so on. Additionally, there is the question of the extent to which consumers themselves may develop (e.g. content creation and/or distribution) platforms, or at least strongly influence them. This is a separate question related a.o. to participation, interactivity and access.

The second step in present regulation is that of market analysis. It is analysed what the relative weight (i.e. the market share) is of various businesses operating within a defined market, and whether there are sufficient opportunities for other companies to enter the market with chances of success, or to further develop themselves. The assessment of whether a market functions well or not is again based on competition rules. Three criteria are important in this respect, i.e. high and non-temporary barriers to entry in a market, the dynamic state of competition behind these barriers to entry, and the question of whether existing competition law is sufficient or not. The level of competition is assessed by analysing substitutability on the demand as well as the supply side, using the hypothetical monopolist test for groups of services that are used by consumers for the same purpose (see e.g. Nihoul \& Rodford, 2004).

The ERG paper (2003) points at four sorts of potential competition issues. This paper is based on the experience of the NRAs, and has been thoroughly checked, over a long period of time, against the European rules. It distinguishes vertical leveraging, horizontal leveraging, single market dominance, and termination. While termination is a typical problem of access markets, and therefore does not directly apply to platforms in general, the three other concepts are very relevant. They pertain to whether or not to regulate ex ante, but also serve as instruments for ex post analyses based on competition law. Related to vertical leveraging, the ERG paper sums up the following standard problems: refusal to deal/denial of access, discriminatory use or withholding of information, delaying tactics, bundling/tying, undue requirements, quality discrimination, strategic design of product, undue use of information about competitors, price discrimination, cross-subsidisation and predatory pricing. For horizontal leveraging, the paper cites bundling/tying on one hand, and cross-subsidisation on the other hand. Finally, for single market dominance (a sort of textbook monopoly behaviour), it distinguishes: strategic design of product or contract terms to raise consumers' switching costs, exclusive dealing, over-investment, predatory pricing, excessive pricing, 
price discrimination, lack of investment, excessive costs/inefficiency and low quality. ${ }^{2}$ These are all important 'touchstones' for regulators, both NRAs and NCAs (National Competition Authorities). A serious complication of such analysis in the context of multi-sided platforms, is that it needs to take into account inter-technological competition, e.g. between DSL, coax, DVB-T and mobile access networks, or between various digital TV and web TV platforms. Furthermore, market share as a measure of dominance or significant market power in multisided markets is harder to establish compared to the access markets that are traditionally scrutinised, and may also be less relevant, given the fact that smaller platform owners may also abuse their power. Also, as the subsequent section will further highlight, the risk of market distortions will be different for each of the four types of platforms distinguished earlier.

The third step is then to impose remedies, if necessary. The European framework foresees a number of measures that can be taken ex ante. They are principally aimed at the wholesale market and derive from the Access Directive or (related to the retail level) the Universal Service Directive. However, as they essentially pertain to the regulation of networks, they cannot be applied as such for regulating the platforms reviewed here. The most important remedies in the Access Directive in this specific context are: transparency, non-discrimination, accounting separation, co-location and facility sharing, technical standards, price control, cost orientation, and publication and access to information (in the context of potential obligations to grant access to networks/platforms). NRAs can choose to enforce these remedies separately or in combination. Again, several of these remedies appear to be applicable to platform owners, at least if the existing strong suspicions of vertical leveraging, cross-subsidies etc. are upheld (see further). Recently, the EC has gone one step further. Its recommendation on regulated access to Next-Generation Access Networks provides a view of the remedies that a dominant or monopolist access platform owner in the era of fibre access networks can expect.

${ }^{2}$ One important element, applicable to the position of multi-sided platforms, is included in article 3 of the Services Directive: “...that vertical integrated public undertakings which provide electronic Communications networks and which are in a dominant position do not discriminate in favour of their own activities." Reference is naturally also made in the Framework Directive (art. 14 (3)): "Where an undertaking has significant market power on a specific market, it may also be deemed to have significant market power on a closely related market, where the links between the two markets are such as to allow the market power held in one market to be leveraged into the other market, thereby strengthening the market power of the undertaking." 
This Commission Recommendation of 20 September 2010 on regulated access to Next Generations Access Networks lays down the principles that national regulators need to follow in order to face the challenge of the restructuring of the access network markets. This is because investments in fibre to the curb (FTTC) and fibre to the home (FTTH) architectures are promising to fundamentally change the network as well as the business topologies. Existing interconnections in exchanges, even down to the level of street cabinets, that have been introduced by operators in the framework of the unbundling of the local loop (ULL) or of bitstream access (BSA) may lose their function when FTTC and FTTH are introduced. This means that alternative operators not only lose these sunk investments, but they are also obliged to install new interconnection points in the incumbent's network. Such a development strongly undermines the goal of the well-known Ladder of Investment doctrin, and bestows once again a competitive advantage onto the incumbent, i.e. related to adaptations to the network, exclusive information, delaying tactics and so on. This explains the need for a new Recommendation, which is based on the existing Directives but provides guidances to the NRAs on how to deal with the new access market issues.

According to the Recommendation, the NRAs have the assignment to carry out permanent monitoring. They can force the SMP operator to provide a reference offer, impose transparency measures, full and timely information on the deployment of new infrastructure, and even a migration path including maintaining a parallel offering of copper next to the new fiber network; all of this including service level indicators. They have the possibility to enforce reciprocity in the sharing of infrastructure and facilities. The principles of cost orientation as well as non-discrimination are also maintained. At the technical level, the possibility is foreseen to oblige operators to apply common technical standards, independently of the network technology deployed, and to impose a design to allow several operators to deploy infrastructure.

The range of measures is impressive, and essentially forces any operator investing in FTTC and FTTH into a regulatory straightjacket, when this is deemed necessary for a healthy market development. For now, it remains an open question whether this approach, mutatis mutandis, foreshadows the ex ante measures to prevent competitive bottlenecks by new ICT platforms.

In summary, a thorough, preliminary investigation can be recommended of the potential risks that arise as a consequence of the multi-sided nature of many ICT markets, and which may be inspired by the current regulation of access markets. Such investigation must lead to a framework to guide NCAs, NRAs, and the EC. It may also yield two positive and important results, i.e. a harmonised approach among the member states and substantial gains 
in time. It is up to the EC, and in first instance to the BEREC, to conduct this investigation and assess whether ex ante regulation is required, or whether ex post intervention suffices.

Some remarks in this regard can already be made. First, anti-trust and sector-specific approaches towards platform regulation can be complementary, with sector-specific regulation oriented towards a specific concept linked to the goals of regulation, such as the removal of bottlenecks. However, in such a complex situation, a cost-benefit analysis of ex ante regulation is absolutely necessary. The danger of over-regulating and substantially slowing down market developments is real. Second, the new net neutrality regulations may partly provide a basis for a more general platform neutrality discussion. In fact, the new guidelines related to net neutrality foresee that regulators, in defence of consumer interests, have power to set minimum quality levels for functionalities delivered over the platform to various service providers, and to impose transparancy requirements (nature of the service, traffic management techniques, any other limitations such as bandwith caps and connection speed). Third, a range of related, strategic decisions need to be taken at the policy level, e.g. related to the question to what extent national regulation, in view of the international dimension of multisided markets, is still efficient, or should be replaced by European regulation. Finally, there is a need to make a distinction between normal or advantageous and non-acceptable platform strategies, related to e.g. bundling and leveraging strategies, as well as to the different risks posed by different types of platform business models. This will be treated further in the next section.

\section{Towards a Regulatory Framework for Different Platform Models}

Given the fact that recognition of the specific nature of platforms and the associated regulatory concerns came only recently, it is unavoidable that European policy makers and regulators are currently uncertain about the necessity for intervention (i.e. ex ante or ex post), and a fortiori about the basis and methodology for potential intervention. This is partly a consequence of the fact that platform markets do not fit the relevant market scheme as defined in the European system, and partly the consequence of the fact that very diverse types of companies may be involved. Many, if not most of these companies do not have to comply so far to any sector-specific regulation. This also poses the question of regulated access providers being confronted with non-regulated competitors. In addition, the dominant regulatory instrument used in the electronic communication sector, i.e. the analysis of wholesale and retail tariffs, is not always applicable. As indicated earlier, platform companies operating in multi-sided markets may offer product and service bundles, with prices set at each side that are often not cost-oriented, without this necessarily leading to a decrease in 
consumer surplus. Both lawmakers and regulators therefore will have to display a high level of inventiveness in order to deal with these issues in the short term.

The previous section illustrated that several aspects of the current European regulatory framework appear to be relevant for platform markets, provided that a number of modifications are made. However, it also pointed to the danger of overregulation, and of prohibiting perfectly normal platform business models, if all current rules and suspicions are upheld. The challenge is thus to bring together some elements that may serve towards a realistic, forward-looking regulatory framework that can be applied to different platform models.

The first aspect of such a framework is that it needs to operate across different technologies and markets. As argued earlier, given the emphasis of current European legislation and regulation of electronic communications on competition issues in the access market, upstream market developments are largely ignored. However, not only businesses with significant market power in access markets may abuse their position at the expense of their competitors and of end users, but increasingly, these access providers are dependent upon service providers, content providers, software and hardware manufacturers that are also in the position to abuse their power.

The debate on regulating platforms in general is thus much wider than the current net neutrality debate, which is also concerned with the use and abuse of power exerted by platform companies over firms operating outside of their own relevant market, but which typically limits this discussion to network operators. It has been argued that keeping the focus of debate and regulation on only one type of platform companies (i.e. connectivity providers) inhibits the ability of these companies to effectively compete with other types of platform owners, in terms of organising ecosystems and presenting an attractive service portfolio to their customers. While most European observers appear to agree that it would be premature to abandon interconnection regulation, local loop unbundling and bitstream access rules, especially in the context of so-called next generation networks, the roll-out of fibre access networks, and the 'Ladder of Investment' hypothesis that most European regulators continue to adhere to, it has also been remarked that there is an imbalance with (the absence of) regulation of other types of platforms, which may have inter alia detrimental effects related to privacy, IPR and access to pluriform content and services. This calls for a regulatory approach that takes into account all market levels or 'layers' involved in the platform business model, as well as in competing platform business models (see also Renda, 2010).

The second aspect is to focus on the logic of platform businesses and to withhold remedies that would penalise 'normal' platform behaviour. While the competition issues that 
are distinguished by the current EU framework, as highlighted previously, can constitute an effective method for a theoretical and anticipatory analysis with regard to the types of platforms that pose most risks, it is far less evident that all the current remedies are useful in this new context (in this regard, see also the discussion in the section on policy concerns related to platforms in general). The bundling of services, the employment of cross subsidies, and temporary selling below cost at one side of the market may all be acceptable in platform markets, as they may lead to consumer surplus in the longer term.

Still, measures such as transparency, non-discrimination and the obligation to negotiate (if necessary under supervision), may be relevant in various cases. And the more classical instruments of competition law, as translated into the measures of the Universal Access Directive, will be appropriate in a number of instances. Yet, as argued earlier, it is far from evident that these ought to be applied ex ante.

In addition, when determining dominance or significant market power, it needs to be considered that market share as a measure of dominance or significant market power in multisided markets is harder to establish, compared to the access markets that are traditionally scrutinised, and may also be less relevant, given the fact that smaller platform owners may also abuse their power through exclusivity measures, raising switching costs and so on. Still, it would appear sensible that platforms with less than 25 or $50 \%$ (with the exact threshold to be investigated further) would be, as a rule, exempt from any particular regulation. It needs to be noted in this respect that the consumer market is an essential part of a market analysis aiming to establish significant market power.

The third aspect is to consider different types of platform business models. As argued earlier, there have been several pleas to reorient the sector-specific framework towards the removal of specific bottlenecks. The platform typology as described earlier highlights different types of value and control configurations around bottleneck functionalities that platform owners employ. This typology identifies all actors involved in ICT service provision and consumption in a more abstract manner, and attempts to position them within a simple framework that enables an evaluation of their relative position within the struggle for platform leadership, and that may be fairly robust to technological and economic evolutions. What we propose is that such a platform typology, based on the distinction between having control or not over the customer relationship, and having control or not over many or most of the assets to ensure the overall value proposition, allows the assessment of a number of competition issues in an anticipative manner. This relates to questions such as who has dominance within a complex ecosystem of actors, who possesses the strongest bargaining position, who may function as a competitive bottleneck, and who may lock-in users. 
It is clear that, while every platform may have dominance within the market where it is primarily active, not all types that we distinguish are as likely to bring about risks related to market distortion and abuse in complementary markets such as the supply of content and applications, the eventual service provision, and so on. Table 2 proposes a number of hypotheses related to the specific platform-related concerns, over and beyond the 'normal' antitrust concerns that each type of economic actor may bring about. It indicates that at least one platform model, i.e. the neutral platform, is unlikely to be sufficiently dominant to lead to strong anti-competitive risks at either side of the platform. Also, two other types only partially pose potential platform-specific concerns.

Table 2: Platform Types and Regulatory concerns

\begin{tabular}{|c|c|c|}
\hline & No Control over Customers & Control over Customers \\
\hline \multirow{3}{*}{$\begin{array}{l}\text { No } \\
\text { Control } \\
\text { over } \\
\text { Assets }\end{array}$} & Neutral Platform & Broker Platform \\
\hline & $\begin{array}{l}\text { The platform owner is strongly reliant } \\
\text { on the assets of other actors to create } \\
\text { the value proposition, and does not } \\
\text { control the customer relationship }\end{array}$ & $\begin{array}{l}\text { The platform owner is strongly reliant } \\
\text { on the assets of other actors to create } \\
\text { the value proposition, but does control } \\
\text { the customer relationship }\end{array}$ \\
\hline & $\begin{array}{l}\text { Regulatory concerns: } \\
\text { - } \quad \text { no specific concerns }\end{array}$ & $\begin{array}{l}\text { Regulatory concerns: } \\
\text { - Customer lock-in (raising switching } \\
\text { costs) } \\
\text { - Price squeeze of service / content } \\
\quad \text { providers }\end{array}$ \\
\hline \multirow{3}{*}{$\begin{array}{l}\text { Control } \\
\text { over } \\
\text { Assets }\end{array}$} & Enabler Platform & System Integrator Platform \\
\hline & $\begin{array}{l}\text { The platform owner controls many of } \\
\text { the necessary assets to ensure the value } \\
\text { proposition, but does not control the } \\
\text { customer relationship }\end{array}$ & $\begin{array}{l}\text { The platform owner controls many of } \\
\text { the assets to ensure the value } \\
\text { proposition, and establishes a } \\
\text { relationship with end-users. Entry of } \\
\text { 'third-party' service providers is } \\
\text { actively encouraged }\end{array}$ \\
\hline & $\begin{array}{l}\text { Regulatory concerns: } \\
\text { - } \quad \text { Refusal to deal } \\
\text { - } \quad \text { Strategic design of products }\end{array}$ & $\begin{array}{l}\text { Regulatory concerns: } \\
\text { - Customer lock-in (raising switching } \\
\text { costs) }\end{array}$ \\
\hline
\end{tabular}




\begin{tabular}{|l|l|l|}
\hline (interoperability) & - & Price squeeze of service / content \\
& providers \\
Lock-in of service/content & - & Refusal to deal \\
& $-\quad \begin{array}{l}\text { Strategic design of products } \\
\text { (interoperability) }\end{array}$ \\
& $\begin{array}{l}\text { Lock-in of service/content } \\
\text { providers }\end{array}$ \\
& $-\quad$ Cross-subsidisation \\
\hline
\end{tabular}

The table can be interpreted as follows. While a neutral platform may be a dominant company, or a company with significant market power, it most probably cannot block other businesses in ways that cannot be resolved ex post by traditional competition law. Google, at the moment of its search engine-focused business model, may be the best example of such a platform. Meanwhile, however, Google's ambitious extension of the platforms which it operates (e.g. Chrome, Android), and the end-user services which it offers (e.g. Gmail, Google Voice) probably require the company to be classified as another type of platform. Such business model evolution implies that regulators should not adopt a static approach, but should regularly monitor the market dynamics.

The broker platform entails a number of additional risks related to its control over the customer relationship. These include customer lock-in (through raising switching costs) and overcharging service / content providers beyond what can be classified as 'normal' platform unbalances between the different sides of the market (see earlier). The enabler platform implies a number of additional risks related a.o. to refusal to deal, the strategic design of products, i.e. through various (non-)interoperability strategies, and the lock-in of service/content providers.

Finally, the system integrator platform combines the potential concerns of the other types, and in addition may give rise to specific cross-subsidisation concerns. It has been argued that cross-subsidisation arguments in platform markets should be considered with some distrust. However, this does not mean that such concerns are always unfounded, in cases when platform owners are themselves also active at both sides of the platform.

In summary, any 'platform-aware' regulatory framework, based on the EU tradition of regulating electronic communications markets, needs to operate across different technologies and markets, needs to focus on the logic of platform businesses and to withhold remedies that would penalise 'normal' platform behaviour, and needs to take into account different types of 
platform business models. Furthermore, any typology used to characterise platform markets should be based on an analysis of the market situation, and provides an indication of competition issues that may be expected, or may not be ruled out. The preliminary overview of regulatory concerns associated with specific platform types, as presented here, would suggest that platform regulation will be first and foremost useful when a system integrator platform has dominance or significant market power related to a 'layered' or 'multilevel' market.

\section{Conclusion: Some Prescriptive Suggestions}

The rise of platforms in ICT markets invites a reappraisal of regulatory frameworks and practices. As platforms originating in entirely different sectors increasingly compete directly against each other, regulators ought to address platform competition issues regardless of their sector of origin, and taking into account the specificities of two-sided or multi-sided market business models. This paper identified different types of such business models in ICT markets. They differ primarily as to the control and value logic embedded in them. A tentative exploration of how such aspects could be taken on board for the regulation of electronic communications and ICT markets in Europe, pointed at a number of specific concerns that may arise related to specific platform types, and at a number of instruments available to current NRAs to address these concerns.

It also briefly highlighted current debates and guidelines on net neutrality and the regulation of next-generation access platform providers, and their relevance for a potential expansion of such approaches to platforms in general. However, from this exploration, it appears far from certain that ex ante regulation of platforms will prove to be necessary, and certainly not as a general rule for all types of platforms. Still, further anticipative investigations ought to shed more light on the potential risks of market distortion and on a converged framework that may help NCAs and NRAs to be responsive to current market developments.

So far, the European Commission has adopted a rather reactive attitude vis-à-vis the competitive relationships of ICT platforms. The Commission has mainly relied on classical competition rules to support a number of ex post reactions. As argued in this paper, a shift towards a more proactive attitude can be expected, and to a certain extent, welcomed. In light of the very limited grip of the NRAs and NCAs, especially those of small member states, on the development and conduct of international platforms, it is advisable to anticipate some of the measures at the European level. 
At the very least, the EC should concern itself with the division of responsibilities between the EC (in collaboration with BEREC) and the NRAs related to these aspects; the potential issuing of ex ante recommendations or guidelines to Member States; and whether to provide guidance to platform owners on the possibility and modalities of incurring (ex post) investigations by the Commission or the NRAs because of certain strategies.

One approach that seems appropriate is that the EC, on the basis of a theoretical definition of markets, centred on various platform business models, implements an instrument to describe the situations that would incur the largest risks of distorting the market in a more detailed manner, and subsequently develops the most appropriate regulatory tools. It appears that a number of sector-specific analytical tools may be helpful. Also, analysis may be partly be inspired by the existing remedies of the Directives and the recent Recommendation of September 2010 related to next-generation access networks. This would enable regulators to intervene more rapidly and more coherently, when and if necessary, without leading to static, ex ante regulatory measures or resorting to overregulation.

The list of regulatory concerns specific to different platform types indicated that they relate to regulatory instruments already foreseen in the present NRA toolset. First and foremost, they refer to monopolisation rules and antitrust rules, and furthermore to transparency measures, obligation to negotiate, non-discrimination, quality of service thresholds, imposing interoperability and/or common technical standards and lastly cost orientation. In any case, it appears that sound and extensive business model analysis is crucial to inform regulators in which cases such measures need to be taken.

\section{Acknowledgements}

The authors wish to thank their colleagues at [to be inserted], as well as the anonymous reviewers, for their helpful comments on previous versions of this article.

\section{References}

Arino, M. (2007) "Content Regulation and New Media: A Case Study of Online Video Portals", Communications \& Strategies, no. 66, 2nd quarter 2007, 115-135.

Armstrong, M. (2004) Competition in Two-Sided Markets. mimeo, University College, London.

Baldwin, C. (2007) "Where do transactions come from? Modularity, transactions, and the boundaries of firms", Industrial and Corporate Change, December 2007, 1-41. 
Baldwin, C. \& K. Clark (2000) Design Rules: The Power of Modularity. MIT Press, Cambridge.

Baldwin, C. \& K. Clark (2006) Architectural Innovation and Dynamic Competition: The Smaller "Footprint” Strategy. HBS Working Paper 07-14.

Ballon, P. (2007a) "Business Modelling Revisited: The Configuration of Control and Value", info: The Journal of Policy, Regulation and Strategy for Telecommunications, Information and Media, 9, 5 (August 2007), 6-19.

Ballon, P. (2007b) "Editorial: The Redesign of Mobile Business Models", info: The Journal of Policy Regulation and Strategy for Telecommunications, Information and Media, 9, 5 (August 2007), 3-5.

Ballon, P. (2009) "The Platformisation of the European Mobile Industry", Communications \& Strategies, 75 ( $3^{\text {rd }}$ Quarter 2009), 15-33.

Baye, M.R. \& J. Morgan (2001), "Information Gatekeepers on the Internet and the Competitiveness of Homogeneous Product Markets", American Economic Review, 91, 454474.

Boudreau, K. (2005) The Boundaries of the Platform: Vertical Integration and Economic Incentives in Mobile Computing. MIT Sloan Research Paper 4565-05.

Boudreau, K. \& A. Hagiu (2009) "Platform Rules: Multi-Sided Platforms as Regulators", in: Gawer, A. (ed.) (2009) Platforms, Markets and Innovation. Cheltenham, UK and Northampton, US: Edward Elgar.

Bresnahan, T. (1999) "New Modes of Competition and the Future Structure of the Computer Industry", in: Eisenach, J. \& T. Lenard (eds.) Competition, Innovation, and the Microsoft Monopoly. Berlin, Germany: Springer.

Caillaud, B. \& B. Jullien (2003) "Chicken and egg: competition among intermediation service providers", Rand Journal of Economics, 34, 2, 309-328.

Cave, M. (2004) "Economic aspects of the new regulatory regime for electronic communications services", in: Buigues, P. \& P. Rey (eds.) The Economics of Antitrust and Regulation in Telecommunications: Perspectives for the New European Regulatory Framework, Edward Elgar, 27-44.

Church, J. \& N. Gandal "Platform Competition in Telecommunications", in: Majumdar, S., Vogelsang, I. \& M. Cave (eds.) (2005), Handbook of Telecommunications Elsevier, 119-153. 
Colfer, L. (2007) The mirroring hypothesis: theory and evidence on the correspondence between the structure of products and organizations. Harvard Business School Working Paper.

Cortade, T. (2006) “A Strategic Guide on Two-Sided Markets Applied to the ISP Market”, Communications \& Strategies, 61 ( $1^{\text {st }}$ Quarter 2006), 17-35.

De Streel, A. (2004) "Remedies in the European Electronic Communications Sector", in: Gérardin, D. (ed.) Remedies in network industries: EC competition law vs. sector-specific regulation, Intersentia, 67-124.

De Streel, A. (2008) "The Relationship between Competition Law and Sector Specific Regulation: The case of electronic communications", Reflets et Perspectives, XLVII, 2008/1, 53-70.

Eisenmann, T. (2007) Managing Proprietary and Shared Platforms: A Life-Cycle View. Harvard Business School Technology \& Operations Management Unit, Research Paper No. 07-105, 27 June.

ERG (2005) ERG Working paper on the SMP concept for the new regulatory framework. ERG.

Ernst, D. (2005) "Limits to Modularity: Reflections on Recent Developments in Chip Design", Industry and Innovation, Vol. 12, No. 3, 303-335, September 2005, 303-335.

Evans, D. S. (2003) “Some Empirical Aspects of Multi-Sided Platform Industries", Review of Network Economics, 2 (September 2003), 191-209.

Evans, D., Hagiu, A. \& R. Schmalensee (2005) "A Survey of the Economic Role of Software Platforms in Computer-based Industries", CESifo Economic Studies, 51 (FebruaryMarch 2005), 189-224.

Farrell, J. \& P. Weiser (2003) "Modularity, Vertical Integration, and Open Access Policies: Towards a Convergence of Antitrust and Regulation in the Internet Age", Harvard Journal of Law \& Technology, Vol. 17, 1, Fall 2003.

Gawer, A. \& M. Cusumano (2002) Platform leadership: how Intel, Microsoft, and Cisco drive industry innovation. Boston, Massachusetts: Harvard Business School Press.

Gawer, A. (ed.) (2009) Platforms, Markets and Innovation. Cheltenham, UK and Northampton, US: Edward Elgar.

Greenstein, S. (2009) “Open platform development and the commercial Internet", in: Gawer, A. (ed.) (2009) Platforms, Markets and Innovation, Edward Elgar, 219-248. 
Jacobides, M., Knudsen, T. \& M. Augier (2006) "Benefiting from innovation: Value creation, value appropriation and the role of industry architectures", Research Policy, 35 (October 2006), 1200-1221.

Johnson, K. (2009) "The importance of net neutrality to the digital economy", Telecommunications Journal of Australia, 59, 2, 19.1-19.16.

Jullien, B. (2004) Two-Sided Markets and Electronic Intermediation. IDEI Working Papers 295, Institut d'Économie Industrielle (IDEI), Toulouse, France.

Langlois, R. (2003) "The Vanishing Hand: the Changing Dynamics of Industrial Capitalism," Industrial and Corporate Change, 12 (2), 351-385.

Larouche, P. (2000) Competition Law and Regulation in European Telecommunications, Hart.

Lewin, K. (1951) Field Theory in Social Science: Selected theoretical papers (D. Cartwright, Ed.). New York: Harper Torchbooks.

Marsden, C. (2010) Net Neutrality: Towards a Co-regulatory Solution. London: Bloomsbury.

McGrath, M. (2001) Product Strategy for High Technology Companies: Accelerating Your Business to Web Speed. New York: McGraw-Hill.

Meyer, M.H. \& J.M. Utterback (1993) "The Product Family and the Dynamics of Core Capability”, Sloan Management Review, 34 (Spring 1993), 29-47.

Mikkola, J. \& P. Hansen (2005) "Defining platform templates", Proceedings of the International Product Development Conference, Copenhagen, Denmark, June 13-14, 1073 1086.

Nihoul, P. \& P. Rodford (2004) EU Electronic Communications Law, Oxford University Press, 2004.

Pardolesi, R. \& A. Renda (2004) The European Commission's Case against Microsoft: Fool Monti Kills Bill? LE Lab Working Paper AT-07-04. Draft version, 19 August 2004.

Parker, G. \& M. Van Alstyne (2008) Innovation, Openness, and Platform Control. Working Paper. 24 July.

Pavitt, K. (2003) "Specialization and Systems Integration: Where Manufacture and Services Still Meet", in: Prencipe, A., Davies, A. \& M. Hobday (eds.) The Business of Systems Integration. Oxford: Oxford University Press, 78-94. 
Poel, M., Renda, A. \& P. Ballon (2007) "Business model analysis as a new tool for policy evaluation: Policies for digital content platforms", INFO: The journal of policy, regulation and strategy for telecommunications, information and media, 9 (5), 86-100.

Renda, A. (2008), I own the Pipes, You call the Tune: The net neutrality debate and its (ir)relevance for Europe, CEPS Special Report.

Renda, A. (2010) "Neutrality and Diversity in the Internet Ecosystem", SMIT 2010 Lecture Series, Brussels (B), 24 Nov 2010.

Richards, P. (2006): "The limitations of market-based regulation of the electronic communications sector", Telecommunications Policy, 30, 201-222.

Rochet, J.C. \& J. Tirole (2003) "Platform Competition in Two-Sided Markets", Journal of the European Economic Association, 1 (June 2003), 990-1029.

Roson, R. (2005) “Two-Sided Markets: A Tentative Survey”, Review of Network Economics, 4 (June 2005), $142-160$.

Salonen, P.I. (2004) Evaluation of a Product Platform Strategy for Analytical Application Software. Dissertation, Helsinki School of Economics.

Schiff, A. (2003) “Open and Closed systems of Two-sided Networks," Information Economics and Policy, 15 (December 2003), 425-442.

Shoemaker, P. (1996) “Media Gatekeeping”, in: Salwen, M. \& D. Stacks (eds.) An Integrated Approach to Communication Theory and Research, Lawrence Erlbaum Associates, 79- 92.

Spulber, D. (2009) Solving the Circular Conundrum: Communication and Coordination in Two-Sided Markets. Northwestern University, October 2009. Retrieved at http://www.law.northwestern.edu/searlecenter/uploads/Spulber_CircularConundrum.pdf

West, J. (2003) "How open is open enough? Melding proprietary and open source platform strategies", Research Policy, 32 (July 2003), 1259-1285.

Wheelwright S.C. \& K.B. Clark (1992) “Creating Project Plans to Focus Product Development”, Harvard Business Review, 70 (March-April 1992), 1-16.

Williamson, B. \& P. Marks (2009) Digital Europe”: productivity, convergence and policy. Plum Consulting White Paper, January 2009. Retrieved online at http://www.plumconsulting.co.uk/pdfs/Digital\%20Europe\%2026\%20January\%202009.pdf

Wright, J. (2004) “One-sided Logic in Two-sided Markets", Review of Network Economics, Vol.3, Issue 1- March 2004. 